FORUM

\title{
Bijzondere opsporingsmethoden onder bijzondere omstandigheden
}

De Wet inzake de regeling van bevoegdheden tot het vorderen van gegevens en de positie van de medisch hulpverlener besproken

Mw.mr.dr.W.L.J.M. Duijst ${ }^{I}$

In dit artikel bespreek ik de Wet tot wijziging van de Wet bijzondere opsporingsmethoden (Wet Bob) inzake vordering van gegevens die op j januari 2006 in werking is getreden. ${ }^{2}$ De meesten van u zullen de Wet Bob associëren met zware criminaliteit, het aftappen van telefoons en het plaatsen van afluisterapparatuur, zaken waar de gezondheidsjurist en arts niet dagelijks mee te maken heeft. Op het eerste gezicht lijkt deze wetswijziging ook weinig te maken te hebben met de gezondheidszorg of het gezondheidsrecht. Echter, bepaalde regelingen kunnen, hoewel zij niet primair bedoeld zijn voor de gezondheidszorg, effect hebben op de gezondheidszorg. Dat bleek onder andere uit de beschouwing van Van Buuren in Medisch Contact van september 2004 over de uitleveringswet. In dit artikel stelt Van Buuren dat de uitleveringswet betekenis kan hebben voor artsen die in Nederland abortus plegen bij iemand afkomstig uit een land waar abortus verboden is. ${ }^{3}$

De Wet vordering gegevens behelst een wijziging van de Wet Bob en enige andere artikelen. ${ }^{4}$ En als de gezondheidszorg ergens veel van heeft is het van gegevens en wel gegevens die niet voor derden bedoeld zijn en zeker niet gevorderd zouden moeten kunnen worden. Een nader onderzoek naar de eventuele betekenis van deze wet voor de gezondheidszorg lijkt dan ook op zijn plaats.

De mogelijkheid tot vordering van gegevens is niet nieuw. In de voormalige artikelen I25i en I25j van het Wetboek van Strafvordering (Sv; beide artikelen vielen buiten de Wet Bob) werd de vordering van de gegevens, de doorzoeking daartoe en het bij doorzoeking onderzoeken van geautomatiseerde werken die zich elders bevonden, geregeld. In artikel I25l Sv was de verschoninggerechtigde vrijgesteld van het gehoor geven aan deze vordering. Deze wetsartikelen zijn gewijzigd. In het nieuwe artikel I25i

\footnotetext{
I. Wilma Duijst is universitair docent strafrecht aan de Radboud Universiteit Nijmegen.

2. Verder te noemen 'Wet vordering gegevens'.

3. J. van Buuren, 'Vogelvrij in Europa', MC 2004, p. I466-I467. Staatssecretaris Ross-van Dorp van VWS gaf als geruststellende reactie dat uitlevering mogelijk was, maar dat zij niet van plan was Nederlandse artsen die zich aan Nederlandse wetgeving houden uit te leveren aan een ander land (www.medischcontact.artsennet.nl).
}

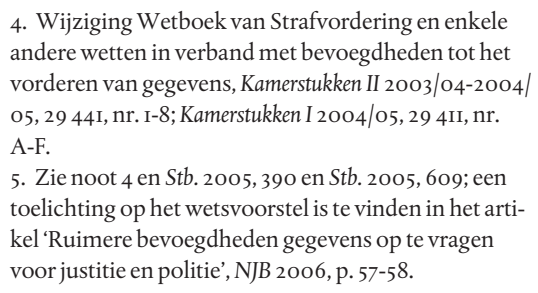

4. Wijziging Wetboek van Strafvordering en enkele andere wetten in verband met bevoegdheden tot het vorderen van gegevens, Kamerstukken II 2003/04-2004/ 05, 29 44I, nr. I-8; Kamerstukken I 2004/05, 29 4II, nr. A-F.

5. Zie noot 4 en Stb. 2005, 390 en Stb. 2005, 609; een toelichting op het wetsvoorstel is te vinden in het artikel 'Ruimere bevoegdheden gegevens op te vragen voor justitie en politie', NJB 2006, p. 57-58. 
Sv wordt de doorzoeking ter vastlegging van gegevens geregeld. In artikel I25j Sv blijft het bij doorzoeking onderzoeken van geautomatiseerde werken elders geregeld. Het onderzoek moet beperkt blijven tot datgene waartoe degene bij wie de doorzoeking plaatsvindt normaal gesproken bevoegd is. Het oude artikel I $25 \mathrm{~Sv}$, waarin de verschoningsgerechtigde werd vrijgesteld van het verschaffen van gegevens, is vervallen. Dit roept vragen op omtrent de positie van de verschoningsgerechtigde. ${ }^{6}$ Artikel I25l $\mathrm{Sv}$ is vervangen door een regeling waardoor het vorderen van gegevens beperkt wordt tot gegevens die afkomstig zijn van de verdachte.

Het deel van de wet dat handelt over de Wet Bob gaat uit van het strafvorderlijke principe van proportionaliteit en subsidiariteit. De uitwerking van dit principe brengt met zich mee dat de algemene bevoegdheid tot inbeslagneming niet wordt aangewend indien de bevoegdheid van vordering van gegevens volstaat om het nagestreefde doel te bereiken. Verder betekent het dat hoe zwaarder het delict is, hoe zwaarder de bevoegdheid die kan worden aangewend en hoe zwaarder de bevoegdheid is, hoe hoger de autoriteit moet zijn die van deze bevoegdheid gebruik kan maken.

In de wet wordt gesproken over drie soorten gegevens: identificerend, anders dan identificerend en gevoelige gegevens. Identificerende gegevens zijn gegevens betreffende naam, adres, woonplaats, geboortedatum, geslacht en administratieve kenmerken. Administratieve kenmerken zijn de gegevens betreffende de relatie tussen degene die de gegevens moet verstrekken en de persoon wiens gegevens worden opgevraagd en de kenmerken van de diensten die de derde aan de persoon in kwestie verleent, zoals een klantnummer en een polisnummer. Andere dan identificerende gegevens zijn gegevens zoals de duur, de data, de plaats en aard van de dienstverlening. Gevoelige gegevens zijn gegevens als bedoeld in artikel I6 Wet bescherming persoonsgegevens (WBP), dat wil zeggen gegevens over godsdienst, ras, politieke gezindheid, gezondheid ${ }^{7}$ of seksuele leven.

In de wet worden drie soorten bevoegdheden besproken, te weten het vorderen van gegevens, doorzoeking om de gegevens te verkrijgen en het bevel om de gegevens te ontsleutelen. De verschillende bevoegdheden zijn steeds geformuleerd in een artikel voor delicten waarvoor voorlopige hechtenis is toegestaan (art. 67 Sv) en in een artikel voor samenspanning (art. 1260 Sv).

De bevoegdheid om gegevens te vorderen ligt bij de opsporingsambtenaar, dat wil zeggen de officier van justitie, de ambtenaar van politie en de buitengewone opsporingsambtenaar. ${ }^{8}$ Het bevel tot vordering van gegevens kan aan eenieder worden gegeven behalve de verdachte zelf. ${ }^{9}$ Het bevel is schriftelijk en moet een vermelding

6. Zie bijvoorbeeld R. van der Hoeven en M.J.C. Visser, 'Identificatie- en meldplicht van de advocaat, een frontale aanval op de geheimhoudingsplicht en het verschoningsrecht', NJB 2003, p. II24-II3I.

7. In paragraaf 4 wordt verder ingegaan op de gegevens betreffende gezondheid.
8. Art. I4I (OvJ en ambtenaar van politie) en I42 Sv (buitengewone opsporingsambtenaar). 9. Art. I26nc en I26uc Sv voor identificerende gegevens, art. I26nd en I26ud Sv voor andere dan identificerende gegevens en art. I26nh en I26uh en art. I26nf en I26uf Sv voor gevoelige gegevens. 
bevatten aan wie de vordering gericht is, het soort gegevens dat wordt gevorderd, de termijn waarbinnen en de manier waarop het een en ander dient te gebeuren. Van de verstrekking van gegevens wordt proces-verbaal opgemaakt.

De bevoegdheid tot doorzoeking ter vastlegging van gegevens die op gegevensdragers zijn opgeslagen komt toe aan degene die bevoegd is om de doorzoeking te doen. ${ }^{\text {Io }}$ De bevoegdheid verschilt dus per plaats die wordt doorzocht. Het strafrecht maakt daarbij onderscheid tussen plaatsen (die geen woning zijn), woningen en kantoren van verschoningsgerechtigden. ${ }^{\text {II }}$

De bevoegdheid tot vordering van ontsleuteling van andere dan identificerende en gevoelige gegevens ligt bij de officier van justitie. ${ }^{\text {I2 }}$ Het bevel kan aan eenieder worden gegeven van wie vermoed wordt dat hij de versleuteling ongedaan kan maken en is vormvrij.

In het strafrecht heeft de verschoningsgerechtigde een speciale positie. Zo is de verschoningsgerechtigde vrijgesteld van aangifteplicht (art. I6o lid $2 \mathrm{~Sv}$ ) en ook voor op handen zijnde delicten bestaat voor de verschoningsgerechtigde geen plicht tot melding (art. 137 Sr). Daarnaast neemt de verschoningsgerechtigde een bijzondere positie in als het gaat om opsporingsbevoegdheden. In artikel 2I $8 \mathrm{~Sv}$ is het verschoningsrecht vastgelegd, in artikel $96 \mathrm{a}$ Sv is de verschoningsgerechtigde vrijgesteld van het voldoen aan een bevel tot uitlevering van voorwerpen ter inbeslagneming, in artikel $98 \mathrm{~Sv}$ is ten slotte een aantal waarborgen ten aanzien van inbeslagneming en doorzoeking bij verschoningsgerechtigden opgenomen. Mocht een beroep op het verschoningsrecht onverhoopt niet slagen dan is het mogelijk om op grond van artikel 552 Sv bezwaar tegen inbeslagneming te maken. In principe heeft dit bezwaar geen opschortende werking, maar in de praktijk wordt gewerkt met enveloppen waarin de gewraakte gegevens worden bewaard tot de rechter een beslissing heeft genomen op het bezwaar. ${ }^{13}$

In de Wet vordering gegevens komt zoals gezegd artikel I25l Sv, waarin de verschoningsgerechtigde wordt vrijgesteld van het verschaffen van gegevens, te vervallen. In de wet is echter rekening gehouden met de positie van de verschoningsgerechtigde en wel door artikel 96a Sv van toepassing te verklaren. De vantoepassingverklaring geldt voor zowel het vorderen van identificerende gegevens, ${ }^{\mathrm{I}}{ }^{4}$ het vorderen van andere dan identificerende gegevens, ${ }^{15}$ als het vorderen van gevoelige gegevens. ${ }^{16}$ De vantoepassingverklaring heeft tot gevolg dat een verschoningsgerechtigde niet hoeft te voldoen aan het gegeven bevel. Tevens lijkt de vantoepassingverklaring van artikel 96a Sv op het vorderen van identificerende gegevens te impliceren dat identificerende gegevens onder het verschoningsrecht vallen. De vanzelfsprekendheid waarmee impliciet

Io. Art. I25i en I25j Sv, in geval van ${ }_{2} 25 \mathrm{j}$ Sv betreft het de doorzoeking waarbij gegevens die elders in geautomatiseerde werken zijn vastgelegd.

II. Zie W.L.J.M. Duijst, 'Opsporing in ziekenhuizen',

DD 2003, p. 96 I-977.

I2. Art. I26nh en I26uh Sv.
I3. Zie Rb. Amsterdam 9 augustus I996, TvGR I997/46 en MC I996, p. II33-II34 en HR 25 september 200I, TvGR 2002/37.

I4. Art. $126 \mathrm{nclid} 3 \mathrm{en}$ I26uc lid $2 \mathrm{~Sv}$.

15. Art. I26nd lid 2 en I26ud lid 2 Sv.

I6. Art. I26nh lid 2 en I26uh lid 2 Sv. 
wordt aangenomen dat identificerende gegevens onder het verschoningsrecht vallen is nieuw; het blijkt zeker niet onverdeeld uit de jurisprudentie. ${ }^{17}$ Pas medio 2004 heeft de Hoge Raad zich hierover uitgelaten. ${ }^{\text {.8 }}$

Naast de vantoepassingverklaring van artikel 96a Sv bevatten de verschillende artikelen voor de verschillende soorten gegevens allen een bepaling dat de vordering geen betrekking kan hebben op onder andere gegevens betreffende gezondheid, seksuele leven en godsdienst. Op deze wijze is een extra waarborg ingebouwd voor gegevens die onder het verschoningsrecht kunnen vallen.

Ten slotte is de mogelijkheid van het maken van bezwaar tegen de vordering ook in het huidige wetsvoorstel opgenomen door artikel 552 Sv uit te breiden met de mogelijkheid van het maken van bezwaar tegen het vorderen van gegevens en de vordering tot ontsleuteling van de gegevens.

Het bevel tot uitlevering van gegevens lijkt netjes geregeld, dus de geheimhouder hoeft zich geen zorgen te maken over het vrij komen van 'geheime' gegevens, of toch wel? De geschiedenis heeft geleerd dat al te groot optimisme over de eerbiediging van de geheimhoudingsplicht door justitie niet op zijn plaats is. ${ }^{19}$ De geheimhouder moet op de eerste plaats worden erkend als verschoningsgerechtigde. Vervolgens moet de opsporingsambtenaar en uiteindelijk ook de rechter accepteren dat de betreffende gegevens onder het verschoningsrecht vallen. Als deze situatie zich voordoet lijkt de positie van de verschoningsgerechtigde veiliggesteld door de artikelen 96a, 98 en 2I 8 Sv, maar dit blijkt in de praktijk niet altijd het geval te zijn. Ook dan nog kan de rechter het opsporingsbelang laten prevaleren boven het belang van geheimhouding. ${ }^{20}$ Reden genoeg om de Wet vordering gegevens met enige voorzichtigheid te benaderen en met een gezondheidsrechtelijke bril te bekijken, alvorens de vlag uit te hangen over de regeling.

Een aantal zaken die in de praktijk problemen kunnen opleveren bij het vorderen van gegevens in een zorginstelling zal ik nu bespreken. Een viertal vragen zal bij het bespreken hiervan als leidraad dienen. Ten eerste de vraag wie beschikking heeft over de gegevens, ten tweede de vraag of de beschikkingsbevoegde persoon verschoningsgerechtigd is, ten derde de vraag of de opgeëiste gegevens onder het verschoningsrecht vallen en ten slotte de vraag wat er moet gebeuren als een beroep op het verschoningsrecht niet geaccepteerd wordt of het opsporingsbelang moet prevaleren boven het belang van geheimhouding.

I7. Kantongerecht Utrecht I3 november 1996, NJ 1997, 4I7. Rb. Den Haag 28 oktober 2003, parketnr. 09/753.296-02, niet gepubliceerd. Hof Amsterdam 9 september 2002, Nieuwsbrief strafrecht 2002, 284. I8. HR 29 juni 2004, NJB 2004, p. I554-I555, TvGR $2005 / 7$.

19. HR 29 juni 2004, NJB 2004, p. 1554-1555, TvGR 2005/7; Rb. Amsterdam 9 augustus I996, TvGR I997/ 46 en MC 1996, p. II33-II34; Rb. Zwolle 4 december
1998, TvGR 1999/20. Rb. Den Haag 28 oktober 2003, parketnr. RK 03/655, niet gepubliceerd. Rb. Amsterdam 2 augustus 2004, NBSTRAF 2004/34I. 20. Zie HR 29 juni 2004, TvGR 2005/7; W.L.J.M. Duijst en T.M. Schalken, 'De plicht om af te zien van het verschoningsrecht of: waar het medisch beroepsgeheim moet wijken voor de opsporing', TvGR 2005, p. 124I34. 
Wie heeft de beschikking over de gegevens?

In een zorginstelling heeft een arts de beschikking over de medische gegevens, de laboratoriumgegevens en de opnamegegevens. De verpleegkundige heeft de beschikking over de laboratorium- en opnamegegevens en vaak ook medische gegevens. Naast deze sleutelfiguren in de zorg zijn er echter anderen die over gegevens kunnen beschikken. Zo heeft de portier/receptiemedewerker toegang tot de opnamegegevens, de laborant tot de laboratoriumgegevens en de raad van bestuur zal in het voorkomende geval kunnen beschikken over alle genoemde gegevens en de personeelsgegevens. Deze ruime beschikbaarheid van de gegevens is noodzakelijk voor het functioneren van een zorginstelling. Bij een bevel tot vordering van gegevens biedt dit echter uitgebreid de mogelijkheid om toegang tot deze gegevens te krijgen. De brede kring van beschikkingsbevoegden maakt de kans groter dat iemand toegang tot de gegevens verschaft.

\section{Is de beschikkingbevoegde persoon verschoningsgerechtigd?}

De arts en verpleegkundige zijn verschoningsgerechtigd op grond van de jurisprudentie. ${ }^{2 \mathrm{I}}$ De portier, de laborante en de leden van de raad van bestuur hebben een afgeleid verschoningsrecht. De afgeleid verschoningsgerechtigde heeft een weliswaar kleine, maar niet te verwaarlozen beslissingsruimte omtrent het al dan niet verschaffen van de gevraagde informatie. ${ }^{22}$

De arts en/of verpleegkundige die wordt geconfronteerd met een (vaak mondeling) bevel tot uitlevering van goederen ter inbeslagneming zal waarschijnlijk op het idee komen dat hij zich kan beroepen op zijn verschoningsrecht. Een arts of verpleegkundige die wordt geconfronteerd met een schriftelijk bevel tot vordering van gegevens in geautomatiseerde werken zal waarschijnlijk op hetzelfde idee komen, maar mogelijk gaan twijfelen door het schriftelijke bevel. Een mondelinge mededeling is nu eenmaal iets anders dan een schrijven waarin iets wordt bevolen. De eis van schriftelijkheid, die bedoeld is als rechtsbescherming, keert zich in dit geval dus eerder tegen degene aan wie het bevel gericht is, dan dat het daadwerkelijk rechtsbescherming biedt. Daar komt bij dat Justitie niet verplicht is om de verschoningsgerechtigde te wijzen op de mogelijkheid van een beroep op het verschoningsrecht. ${ }^{23}$

Voor anderen in een zorginstelling die een afgeleid verschoningsrecht hebben zal het gegeven schriftelijk bevel mogelijk nog eerder dan voor de verschoningsgerechtigde een reden zijn om de gegevens vrij te geven.

\section{Vallen de gegevens onder het verschoningsrecht?}

Duidelijk zal zijn dat medische dossiers die in een geautomatiseerd systeem worden bijgehouden onder het beroepsgeheim/verschoningsrecht vallen. Datzelfde kan gezegd worden van laboratoriumgegevens. Ook opnamegegevens en NAW-gegevens $^{24}$ zullen zonder al te veel moeite onder het verschoningsrecht gebracht kunnen

\footnotetext{
2I. Voor artsen vaste jurisprudentie sinds HR 2I april I9I3, NJ I9I3, p. 958-96I. Voor verpleegkundigen zie onder andere Hof Den Bosch 20 juni i96I, NJ I962, 344; HR 23 november I990, TvGR I99I/I9.

22. HR 25 november 2003 , LJN-nr. AN9oi2, zaaknr.

23-004I53-O2; W.L.J.M. Duijst, Boeven in het ziekenhuis,
}

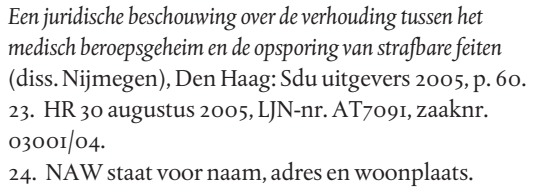

Een juridische beschouwing over de verhouding tussen het medisch beroepsgeheim en de opsporing van strafbare feiten (diss. Nijmegen), Den Haag: Sdu uitgevers 2005, p. 60. 23. HR 30 augustus 2005, LJN-nr. AT709I, zaaknr. 0300I/04. 24. NAW staat voor naam, adres en woonplaats. 
worden. Maar een zorginstelling beschikt over nog andere gegevens, zoals bijvoorbeeld lijsten van bestelde medicatie, lijsten met bloed dat is toegediend en dienstroosters van artsen en verpleegkundigen. Kunnen de medicatielijsten en lijsten van toegediend bloed (met enige ruimdenkendheid) onder gegevens betreffende gezondheid gebracht worden, met dienstlijsten is dat een andere zaak. Deze gegevens hebben geen betrekking op de gezondheid, maar hebben betrekking op personen die eventueel kunnen beschikken over gegevens die betrekking hebben op de gezondheid. Bij het ter beschikking komen van een dienstlijst zal de mogelijkheid om iemand te vinden die bereid is om de politie informatie te verschaffen aanzienlijk verruimd zijn; er is immers maar één medisch hulpverlener nodig die bereid is gegevens te verschaffen.

Wat moet er gebeuren indien een beroep op het verschoningsrecht niet wordt geaccepteerd? In de Wet vordering gegevens wordt artikel 552 Sv van toepassing verklaard op de nieuwe bevoegdheden. Dit betekent dat bezwaar kan worden gemaakt tegen het vorderen van gegevens en het bevel tot ontsleutelen. Deze mogelijkheid is van groot belang voor de bescherming van gegevens die onder het verschoningsrecht vallen. Het probleem van artikel $552 \mathrm{~Sv}$ is het ontbreken van een opschortende werking. $\mathrm{Nu}$ bestond dit probleem al langer als het om gegevens ging die onder het verschoningsrecht vallen. Dit probleem is goed te ondervangen door het aanleveren van de gegevens in een gesloten envelop; alhoewel hierbij moet worden aangetekend dat het aanbod tot het aanleveren in een gesloten envelop niet altijd geaccepteerd wordt. ${ }^{25}$ Een complicerende factor bij computergegevens is dat deze beschikbaar komen zodra een bestand is geopend. Voorstelbaar is dat dit bestand vervolgens ongezien wordt opgeslagen en dat het oordeel van de rechter over het bevel wordt afgewacht. Dit lijkt echter wel heel idyllisch.

Een bevel tot ontsleutelen wordt gegeven of niet gegeven. Ook een bezwaar hiertegen heeft geen opschortende werking. Ook hierbij bestaat het probleem dat de gegevens openbaar worden zodra zij ontsleuteld zijn. Dit betekent dat de politie hangende het bezwaar door kan gaan met het onderzoek en de gevonden gegevens kan gebruiken. Een afdoende manier om de gegevens die onder het verschoningsrecht vallen te beschermen lijkt vooralsnog niet gevonden te zijn met de toepassing van artikel 552 Sv op de nieuwe bevoegdheden.

De Wet vordering gegevens is het prototype van een moderne wet. De wetgever gaat mee met zijn tijd en zorgt dat opsporingsbevoegdheden worden aangepast aan de technologische ontwikkelingen. Hoewel de wetgever rekening heeft gehouden met de 'oude' waarden en normen omtrent het beroepsgeheim, zitten er aan de wet nog wel haken en ogen. Met name in zorginstellingen kan de (in het kader van de werkbaarheid noodzakelijke) ruime beschikbaarheid van gegevens binnen de instelling voor problemen zorgen. Ook de verplichting tot het schriftelijk vastleggen van een bevel zal mogelijk eerder in het nadeel van de verschoningsgerechtigde werken dan in het 
voordeel. Ten slotte biedt de vantoepassingverklaring van artikel 552 Sv op de nieuwe bevoegdheden door het gebrek aan opschortende werking niet voldoende waarborgen tegen het vrijkomen van 'geheime' gegevens.

$\mathrm{Nu}$ de wet is ingevoerd is waakzaamheid van, en goede voorlichting aan het personeel van zorginstellingen over de nieuwe strafvorderlijke bevoegdheden van cruciaal belang. De wet biedt de (afgeleid) verschoningsgerechtigde mogelijkheden om geen gehoor te geven aan bevelen met betrekking tot gegevens, maar het is de verantwoordelijkheid van de (afgeleid) verschoningsgerechtigde om ervoor te waken dat die mogelijkheden ook goed benut worden. 